\begin{tabular}{c|c|c|}
\cline { 3 - 3 } CRITICAL & $\begin{array}{l}\text { Western Ghats } \\
\text { PARTNERSHIP FUND }\end{array}$ \\
Special Series
\end{tabular}

\title{
LENGTH-WEIGHT AND LENGTH-LENGTH RELATIONSHIP OF THREE SPECIES OF SNAKEHEAD FISH, CHANNA DIPLOGRAMMA, C. MARULIUS AND C. STRIATA FROM THE RIVERINE REACHES OF LAKE VEMBANAD, KERALA, INDIA
}

\author{
Anvar Ali ${ }^{1}$, Neelesh Dahanukar ${ }^{2}$ \& Rajeev Raghavan ${ }^{3}$ \\ ${ }^{1,3}$ Conservation Research Group (CRG), St. Albert's College, Kochi, Kerala 682018, India \\ ${ }^{2}$ Indian Institute of Science Education and Research (IISER), Dr. Homi Bhabha Road, Pashan, Pune, Maharashtra \\ 411008, India \\ 2,3 Zoo Outreach Organization (ZOO), 96 Kumudham Nagar, Vilankurichi Road, Coimbatore, Tamil Nadu 641035, India \\ ${ }^{1}$ anvaraliif@gmail.com, ${ }^{2}$ n.dahanukar@iiserpune.ac.in, ${ }^{3}$ rajeevraq@hotmail.com (corresponding author)
}

Abstract: The length-weight relationship (LWR) and length-length relationships (LLR) of three snakehead fishes, Channa diplogramma, C. marulius and C. striata, exploited by small-scale fishers in the riverine reaches of Lake Vembanad, Kerala were studied using the allometric growth equation $Y=a X^{b}$. Our analysis shows that the LWR of $C$. diplogramma and $C$. marulius is nonisometric with exponents much smaller than the cubic value $(b=3)$, while that of $C$. striata is isometric. Channa marulius showed a definite change in LWR with size, with smaller fish growing with positive allometric exponents ( $b$ $>3$ ) and larger individuals having negative allometric relationship $(b<$ 3 ), indicating a possible age-related change in growth pattern. In the case of LLR, all three snakehead species showed non-isometric growth patterns. The caudal fin did not grow substantially with increasing fish length.

Keywords: Allometric relationships, Channidae, snakeheads, southern Western Ghats.
Snakeheads of the genus Channa Scopoli, 1777, are among the most popular food fishes in tropical Asia (Wee 1982). In addition to being a common staple food fish, snakeheads are also consumed therapeutically for wound healing and reducing post-operative pain and discomfort (Gam et al. 2006). These fish are the focus of important small-scale fisheries in rivers and reservoirs throughout their range, and are also popular for pond and cage aquaculture (Adamson 2010; Poulsen et al. 2008). Little is known about their bionomics and demography, and such data are required for developing management measures for both aquaculture and wild fisheries.

Information on allometry is essential to understand

DOI: http://dx.doi.org/10.11609/JoTT.o3353.4769-73 | ZooBank: urn:Isid:zoobank.org:pub:CB35EE3E-8D38-48B3-A9D7-ABFB29A915ED

Editor: M. Afzal Khan, Department of Zoology, Aligarh Muslim University, Aligarh, India.

Date of publication: 26 September 2013 (online \& print)

Manuscript details: Ms \# 03353 | Received 19 September 2012 | Final received 02 September 2013 | Finally accepted 03 September 2013

Citation: Ali, A., N. Dahanukar \& R. Raghavan (2013). Length-weight and length-length relationship of three species of snakehead fish, Channa diplogramma, C. marulius and C. striata from the riverine reaches of Lake Vembanad, Kerala, India. Journal of Threatened Taxa 5(13): 4769-4773; http://dx.doi.org/10.11609/JoTT. 03353.4769-73

Copyright: (c) Ali et al. 2013. Creative Commons Attribution 3.0 Unported License. JoTT allows unrestricted use of this article in any medium, reproduction and distribution by providing adequate credit to the authors and the source of publication.

Funding: The study was carried out as part of a larger project on the conservation of freshwater fishes of Kerala funded by the North of England Zoological Society/ NEZS, Chester Zoo, United Kingdom

Competing Interest: The authors declare no competing interests. Funding sources had no role in study design, data collection, results interpretation and manuscript writing.

Acknowledgements: We thank Fibin Baby for his help and support in the field, K. Krishnakumar for photographs and Siby Philip for his critical comments and valuable suggestions on the draft manuscript. Two anonymous reviewers and Subject Editor provided constructive comments on the draft manuscript.

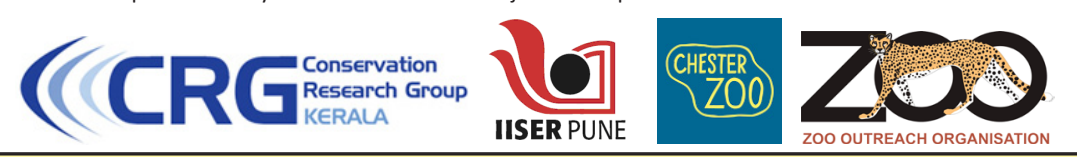

The publication of this article is supported by the Critical Ecosystem Partnership Fund (CEPF), a joint initiative of l'Agence Française de Développement, Conservation International, the European Commission, the Global Environment Facility, the Government of Japan, the MacArthur Foundation and the World Bank. 
the basic growth pattern of a species. Among the allometric relationships, length-weight relationship (LWR) and length-length relationship (LLR) of fishes can indicate species status in an environment and characterize patterns of growth (Froese 2006; Kharat et al. 2008). Allometric relations take the general form of the power law $Y=a X^{b}$ or its logarithmic form $\log Y=b \log X+\log a$, where $X$ and $Y$ are measured quantities, $a$ is the normalization constant and $b$ is the scaling exponent. When scaling is isometric, fish weight (equal to the volume if constant density is assumed) will vary with the length cubed (i.e. $b=3$ ), while the standard length will show linear correlation with total length (i.e. $b=1$; Froese 2006; Kharat et al. 2008). If the observed value of $b$ differs from these expectations the relationship is allometric and growth is non-isometric, and an examination of the contributing factors can shed light on species biology and wellbeing.

In this paper we determine the LWR and LLR of three species of snakeheads, Channa diplogramma, C. marulius and $C$. striata (Images 1-3), targeted by small-scale fishers from the Pampa and Achankovil, two important confluent rivers of Vembanad Lake in the southern Indian state of Kerala.

\section{Materials and Methods}

Our sampling was concentrated on four important landing centres in the Pampa and Achankovil river basin viz., Edathua $\left(9.36^{\circ} \mathrm{N} \& 76.47^{\circ} \mathrm{E}\right)$, Parumala $\left(9.34^{\circ} \mathrm{N}\right.$ \&

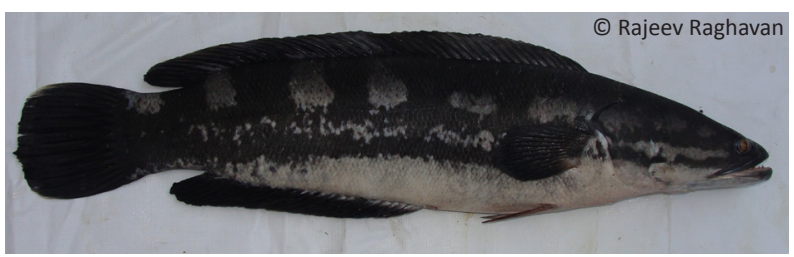

Image 1. Channa diplogramma

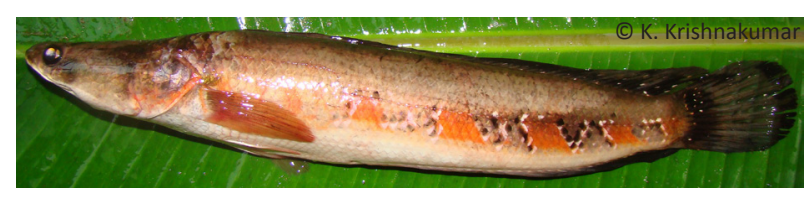

Image 2. Channa marulius

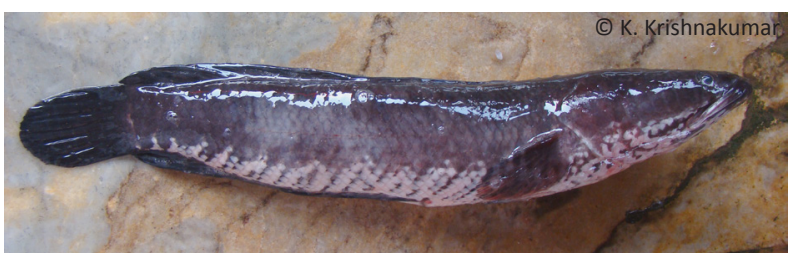

Image 3. Channa striata $\left.76.55^{\circ} \mathrm{E}\right)$, Prayikkara $\left(9.26^{\circ} \mathrm{N} \& 76.54^{\circ} \mathrm{E}\right)$ and Payippad $\left(9.42^{\circ} \mathrm{N} \& 76.58^{\circ} \mathrm{E}\right)$. Payippad is one of the largest fishing villages in the Pampa-Achankovil river basin (Sunil 2007), while Parumala contributes to more than half of the share of exploited fish catches from the Pampa River (Renjithkumar et al. 2011). We visited these four markets for a period of five months (January to May 2010) and measured the total lengths (from tip of snout to end of caudal fin) and standard length (from tip of snout to end of caudal peduncle) in centimeters and weight in grams of $C$. diplogramma, $C$. marulius and $C$. striata that were caught by local fishers. All measurements were taken at the markets and no fish was purchased and brought to the laboratory. A total of 358 individuals (C. marulius, $\mathrm{n}=154$; C. striata, $\mathrm{n}=137$; $C$. diplogramma, $\mathrm{n}=67$ ) were measured during the course of the study.

The LWR was determined using the equation $W=a L^{b}$ (Pauly 1984) and logarithmically transformed into log $W=$ $\log a+b \log L$ where $W$ is the weight of the fish in gram and $L$ is the length ( $L=T_{L}$ or $S_{L}$ ) of the fish measured in centimetre. The parameters $a$ (proportionality constant) and $b$ (exponent) of the LWR were estimated by least square regression (Zar 1999). Goodness of fit was determined using the coefficient of determination $\left(r^{2}\right)$. The null hypothesis that $b=3$ was tested using two tailed $t$ test as described by Zar (1999). The LLR was estimated as $T_{L}=a S_{L}^{b}$ and its log-log form $\log \left(T_{L}\right)=\log (a)+b \log \left(S_{L}\right)$. Goodness of fit was determined using the coefficient of determination $\left(r^{2}\right)$ and the null hypothesis that $b=1$ was tested using two tailed $t$ test.

\section{Results and Discussions}

Snakehead fishes like $C$. marulius and $C$. diplogramma are important food fishes exploited in central Kerala, especially in the Pampa River with annual landings of 30.36 and 0.79 tons, respectively (Renjithkumar et al. 2011). However, populations of snakeheads in the rivers of Kerala have declined considerably due to a variety of factors such as unethical fishing, habitat alterations and diseases (Kurup 2000; Renjithkumar et al. 2011). For example $C$. diplogramma has been categorised as 'Vulnerable' in the IUCN Red List of Threatened Species (Abraham 2011) due to its declining populations and rarity (Benziger et al. 2011).

Analysis of the LWR suggested that both $C$. diplogramma and C. marulius showed a non-isometric growth pattern in the study region, whereas $C$. striata showed an isometric growth pattern. In the case of $C$. diplogramma the exponent of the LWR (Fig. 1a) was 1.28 $(S E=0.06)$ which was significantly lesser than the cubic value ( $t=27.17, d f=60, P<0.0001$ ), while in $C$. marulius 

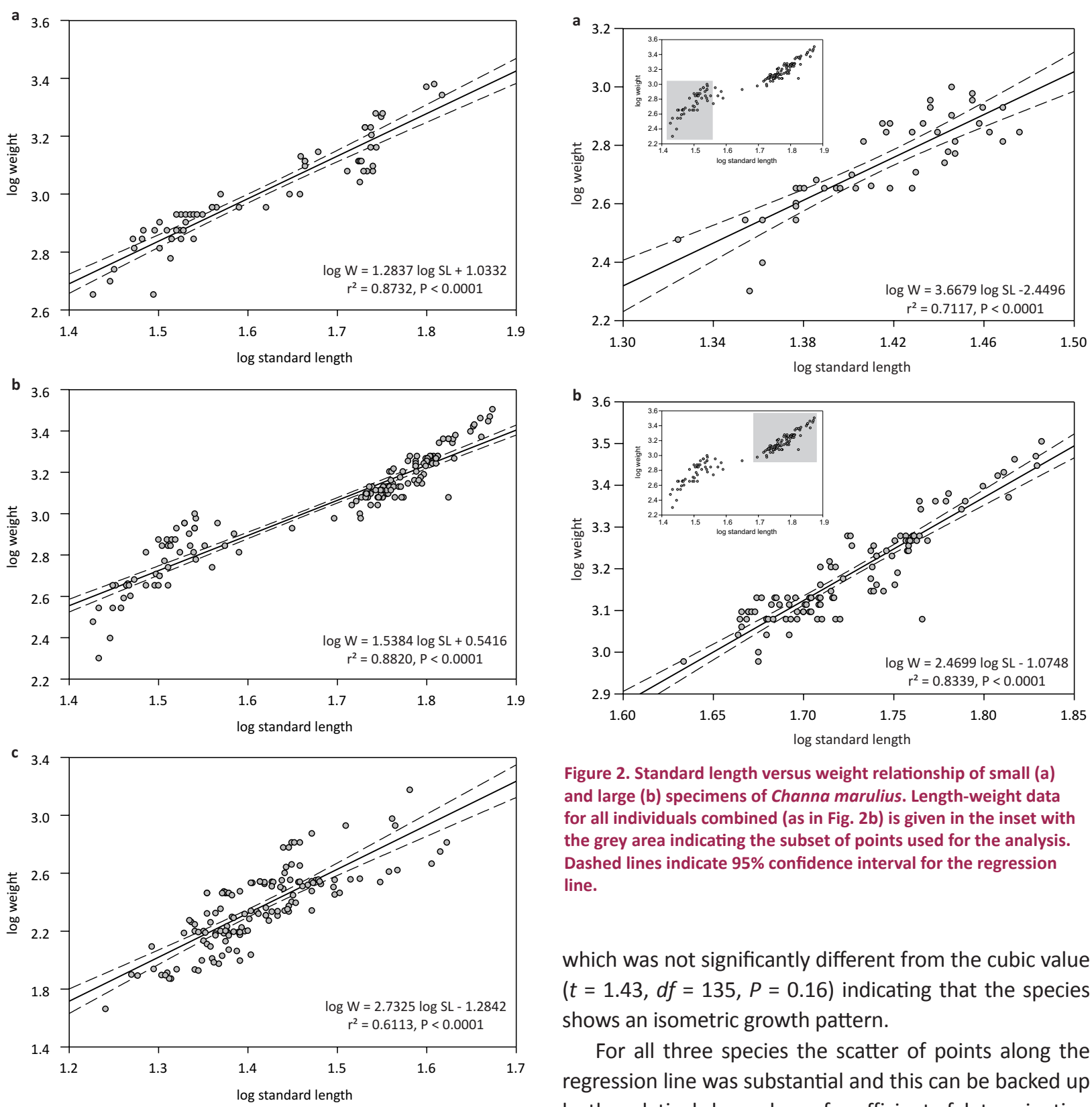

Figure 1. Standard length versus weight relationship of (a) Channa diplogramma, (b) Channa marulius and (c) Channa striata. Dashed lines indicate $95 \%$ confidence interval for the regression line.

(Fig. 1b) it was 1.54 (SE = 0.05) which was also significantly lesser than the cubic value $(t=-11.76, d f=151, P<$ 0.0001 ). These results suggest that both species show non-isometric or negative allometric growth and that the fish do not grow in proportion to the length but the increase in weight occurs with much smaller increments with increase in the length of the fish. This therefore indicates that populations of both $C$. diplogramma and $C$. marulius are not growing isometrically and is likely to have less conditioning (Froese 2006). However, in C. striata, the exponent of the LWR (Fig. 1c) was 2.73 (SE = 0.19)

Figure 2. Standard length versus weight relationship of small (a) and large (b) specimens of Channa marulius. Length-weight data for all individuals combined (as in Fig. 2b) is given in the inset with the grey area indicating the subset of points used for the analysis. Dashed lines indicate $95 \%$ confidence interval for the regression line.

which was not significantly different from the cubic value ( $t=1.43, d f=135, P=0.16$ ) indicating that the species shows an isometric growth pattern.

For all three species the scatter of points along the regression line was substantial and this can be backed up by the relatively low values of coefficient of determination $\left(r^{2}\right)$ which was 0.8732 for C. diplogramma, 0.8820 for C. marulius and 0.6113 for C. striata. Even though it is difficult to predict the exact cause of this disparity it is possible that the observed pattern is a result of difference in the growth pattern at different ages/stages of growth. Nevertheless, we do not have sufficient evidence for this argument for $C$. diplogramma and $C$. striata. However, the pattern in the distribution of the data points along the log weight and log standard length axes in C. marulius clearly shows that the smaller individuals $(21.1-29.9 \mathrm{~cm})$ have a higher slope as compared to larger individuals (38.2-67.9 $\mathrm{cm})$. Therefore, these two ranges were plotted separately (Fig. 2). Smaller C. marulius had an exponent of 3.67 (SE $=0.36$ ) which was marginally higher than the cubic value 


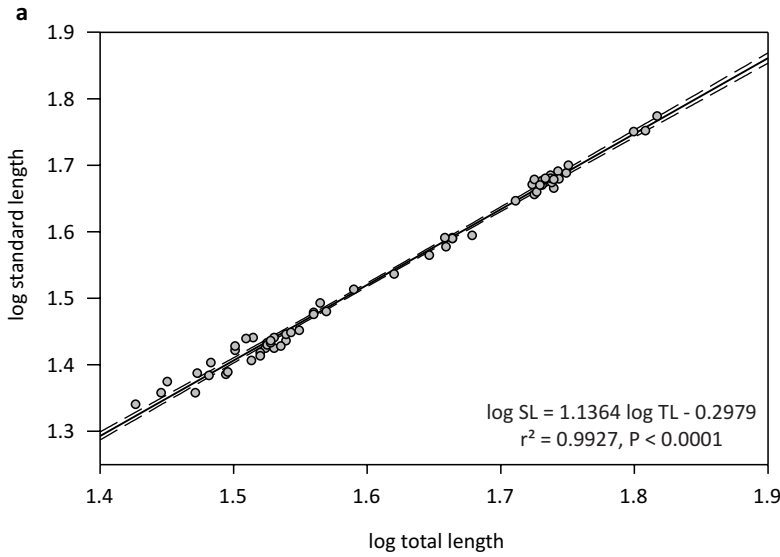

b
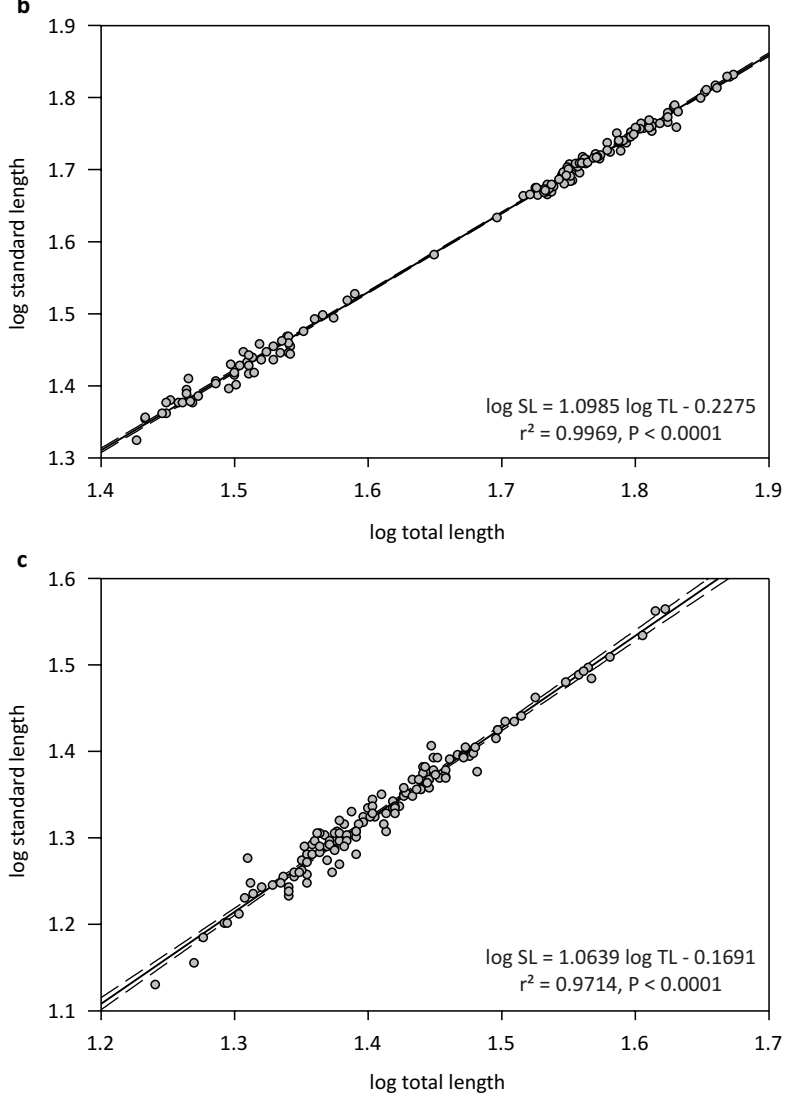

Figure 3. Length-length relationship of (a) Channa diplogramma, (b) Channa marulius and (c) Channa striata. Dashed lines indicate 95\% confidence interval for the regression line.

at one tailed level (one tailed $t=-1.85, d f=42, P=0.035$ ). However, larger $C$. marulius had an exponent of 2.47 (SE $=0.11$ ) which was significantly smaller than the cubic value ( $t=4.83, d f=100, P<0.0001)$. This indicates that in smaller individuals of $C$. marulius the weight increases with higher rate, with increase in the size but the change in the weight as compared to the change in the length slows down in the larger individuals. The exponent for the small and large fish was also significantly different ( $t$ $=4.098, d f=143, P<0.0001)$.
Analysis of the LLR suggested that all the three species of Channa, studied here, had a non-isometric growth pattern. In C. diplogramma the exponent of the LLR (Fig. 3a) was 1.14 (SE $=0.01$ ) which was significantly greater than the value of unity $(t=-10.88, d f=60, P<0.0001)$; in C. marulius the LLR exponent (Fig. 3b) was 1.10 (SE = $0.01)$ which was significantly greater than the value of unity $(t=-19.82, d f=158, P<0.0001)$; and in $C$. striata the LLR exponent (Fig. 3c) was 1.06 (SE $=0.02$ ) which again was significantly greater than the value of unity $(t=-4.10$, $d f=135, P<0.0001)$. Since the difference in the total length and the standard length is due to the caudal fin, the growth of caudal fin is based on the above results. As the standard length was scaling with the total length with the positive allometric relationship with $b>1$ it is obvious that the increase in the standard length was not scaled with the growth in the total length and total length increased at smaller increments with increase in the standard length. Thus, with increase in the length of the fish the caudal fin does not increase proportionately but grows with lesser increments.

Very few studies are available on the LWR and LLR of snakehead fishes from India, and especially so from Western Ghats and the southern states (Froese \& Pauly 2012). There is only one other report on the LWR of C. diplogramma from Tamil Nadu (Ebanasar \& Jayaprakash 2005), while there is no information on the LLR of the species. There are several reports on the LWR of $C$. marulius and $C$. striata from other parts of their distribution but no information on their LLR.

In River Ganga, C. marulius followed isometric growth with a LWR exponent of 3.00 (Khan et al. 2012), while the same species showed non-isometric growth pattern with an LWR exponent of 2.75 in Harike Wetland, Punjab (Dua \& Kumar 2006), 1.45 in the Godavari River (Rathod et al. 2011), 3.32 from Poongar swamp in Bhavanisagar (Devaraj 1973) and 3.16 in Kali River (Ahmad et al. 1990). The negative allometric growth pattern in Harike Wetland and Godavari River or the positive allometric growth pattern in Kali River cannot be validated statistically because the authors have not provided the standard error in b. However, for Bhavanisagar, Devaraj (1973) has shown that the exponent is significantly higher than isometry. In accordance with our results of overall exponent of 1.54 (SE $=0.05)$, it can be suggested that $C$. marulius shows a wide variation in their growth pattern. Length class in three studies (Ahmad et al. 1990; Dua \& Kumar 2006; Devaraj 1973) had strong overlap with the length class considered in our study $(16-80 \mathrm{~cm}, 25-89 \mathrm{~cm}$ and 8-95 $\mathrm{cm}$ respectively versus $21-68 \mathrm{~cm}$ in our study). Therefore the variation in the exponent is not a result of differential 
sampling methods across the studies. Nevertheless, within our study we observed that there was a difference in the exponent for smaller length class as compared to larger length class indicating that the species has two growth stanzas. The smaller individuals $(21.1-29.9 \mathrm{~cm})$ grew with the exponent significantly higher than the cubic value while the larger specimens $(38.2-67.9 \mathrm{~cm})$ grew with exponents significantly smaller than the cubic value. Such ontogenic variations in the cubic law are known from other fish species as well (Froese 2006), however, a more detailed investigation regarding the reasons contributing to such variations is essential. It is important to note that this possibly age related pattern is not universal for different populations of this species. Rathod et al. (2011) studied the LWR in the length class $22-38 \mathrm{~cm}$, which overlapped with our smaller length class, and they found an exponent of 1.45. Further, even though the length class groups considered are not similar to our classes, Devaraj (1973) suggested that the specimens of smaller length class $(<8 \mathrm{~cm})$ had an exponent of 1.18 , while the specimens of larger length class $(>8 \mathrm{~cm})$ had an exponent of 3.33 .

Except for a study by Senguttuvan \& Sivakumar (2010) indicating that C. striata in Ukkadam Lake, Coimbatore showed fast growth (without any information on LWR), there is no other information on the LWR of $C$. striata from southern India to compare our results. Khan et al. (2011) reported the exponent of 2.93 (SE $=0.24$ ) for $C$. striata collected in Ganga River of northern India, while Satrawaha \& Pilasamorn (2009) reported the exponent of 2.94 (SE $=0.22$ ) from Chi River of Thailand. Both these results, similar to our study, vouch for isometric growth of C. striata.

Even though we do not have other reports on LLR of the three species of snakeheads, the fact that all three showed a positive allometric growth indicate that the caudal fin of these species does not increase proportionately with the length of the species, rather it grows with much smaller increments.

\section{REFERENCES}

Abraham, R. (2011). Channa diplogramme. In: IUCN 2012. IUCN Red List of Threatened Species. Version 2012.1. <www.iucnredlist.org>. Downloaded on 08 September 2012

Adamson, E.A.S. (2010). Influence of historical landscapes, drainage evolution and ecological traits on patterns of genetic diversity in South East Asian freshwater snakehead fishes. PhD Thesis submitted to the Queensland University of Technology, Brisbane, Australia, 241p.

Ahmad, M.U., F. Khumar, S. Anwar \& M.S. Siddiqui (1990). Preliminary observations on the growth and food of murrel Channa (= Ophicephalus) marulius Bloch of the river Kali in North India. Journal of Freshwater Biology 2(1): 47-50.
Benziger, A., S. Philip, R. Raghavan, P.H.A. Ali, M. Sukumaran, J.C. Tharian, N. Dahanukar, F. Baby, R. Peter, K.R. Devi, K.V. Radhakrishnan, M.A.K. Haniffa, R. Britz \& A. Antunes (2011). Unraveling a 146 years old taxonomic puzzle: validation of Malabar Snakehead, species-status and its relevance for channid systematics and evolution. PLOS ONE 6(6): e21272; http://dx.doi.org/10.1371/journal.pone.0021272

Devaraj, M. (1973). Biology of the large snakehead Ophicephalus marulius (Ham.) in Bhavanisagar waters. Indian Journal of Fisheries 20: 280-301.

Dua, A. \& K. Kumar (2006). Age and growth patterns in Channa marulius from Harike Wetland (A Ramsar site), Punjab, India. Journal of Environmental Biology 27(2): 377-380.

Ebanasar, J. \& V. Jayaprakash (2005). Length weight relationship of Channa micropeltes (Cuvier) from Pechipparai reservoir, Tamil Nadu. Journal of the Inland Fisheries Society of India 37(1): 60-63.

Froese, R. (2006). Cube law, condition factor and weight-length relationships: history, meta-analysis and recommendations. Journal of Applied Ichthyology 22: 241-253; http://dx.doi.org/10.1111/j.14390426.2006.00805.x

Froese, R. \& D. Pauly, (Eds.) (2012). Fishbase. <www.fishbase.org> accessed $08^{\text {th }}$ Sepetember 2012.

Gam, L-H., C-Y. Leow \& S. Baie (2006). Proteomic analysis of snakehead fish (Channa striata) muscle tissue. Malaysian Journal of Biochemistry and Molecular Biology 14(1): 25-32.

Khan, M.A., S. Khan \& K. Miyan (2012). Length weight relationship of giant snakehead, Channa marulius and stinging catfish, Heteropneustes fossilis from the River Ganga, India. Journal of Applied Ichthyology 28(1): 154-155; http://dx.doi.org/10.1111/j.1439-0426.2011.01901.x

Khan, S., M.A. Khan, K. Miyan \& M. Mubark (2011). Length-weight Relationships for Nine Freshwater Teleosts Collected from River Ganga, India. International Journal of Zoological Research 7(6): 401-405; http:// dx.doi.org/10.3923/ijzr.2011.401.405

Kharat, S.S., Y.K. Khillare \& N. Dahanukar (2008). Allometric scaling in growth and reproduction of a freshwater loach Nemacheilus mooreh (Sykes, 1839). Electronic Journal of Ichthyology 4(1): 8-17.

Kurup, B.M. (2000). Management plans to arrest the decline of freshwater fish diversity of Kerala, pp. 164-166. In: Ponniah, A.G. \& A. Gopalakrishnan (eds). Endemic fish diversity of Western Ghats, NBFGRNATP National Bureau of Fish Genetic Resources, Lucknow, UP.

Pauly, D. (1984). Fish Population Dynamics in Tropical Waters: A Manual for Use with Programmable Calculators. ICLARM. Manila, Philippines, $325 \mathrm{pp}$.

Poulsen, A., D. Griffiths, S. Nam \& N.T. Tung (2008). Capture-based aquaculture of Pangasiid catfishes and snakeheads in the Mekong River Basin. Capture-based aquaculture. Global overview. FAO Fisheries Technical Paper. No. 508. Rome, FAO.

Renjithkumar, C.R., M. Harikrishnan \& B.M. Kurup (2011). Exploited fishery resources of the Pampa River, Kerala, India. Indian Journal of Fisheries 58(3): 13-22.

Rathod, S.R., S.E. Shinde \& P.R. More (2011). Length weight relationship in Salmostoma navacula and Channa marulius Godavari River at Kaigon Toka, Dist Aurangabad (MS) India. Recent Research in Science and Technology 3(3): 104-106.

Satrawaha, R. \& C. Pilasamorn (2009). Length-weight and lengthlength relationships of fish species from the Chi River, northeastern Thailand. Journal of Applied Ichthyology 25(6): 787-788; http://dx.doi. org/10.1111/j.1439-0426.2009.01293.x

Senguttuvan, M. \& A.A. Sivakumar (2010). Observations on the age and growth of Channa striatus (Bloch) in Ukkadam Lake, Coimbatore, Tamil Nadu, India. Indian Journal of Fisheries 57(3): 7-12.

Sunil, D.S. (2007). State interventions and natural resource management: a study on the social interfaces in a riverine fisheries setting in Kerala. Natural Resources Forum 31: 61-70; http://dx.doi.org/10.1111/j.14778947.2007.00128.x

Wee, K.L. (1982). Snakeheads: Their biology and culture, pp. 181-213. In: Muir R, ed. Recent Advances in Aquaculture. Westview, Boulder, CO.

Zar, J.H. (1999). Biostatistical Analysis - Fourth Edition. Pearson Education India, 663pp.

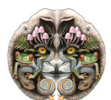

